\title{
Lapurdum
}

Euskal ikerketen aldizkaria | Revue d'études basques |

Revista de estudios vascos | Basque studies review

$19 \mid 2016$

Numéro XIX

\section{Argumentu isilen tipologia bateratu baten aldeko zenbait argudio}

\section{Maia Duguine}

\section{OpenEdition}

Journals

Édition électronique

URL : https://journals.openedition.org/lapurdum/3338

DOI : 10.4000/lapurdum.3338

ISSN : 1965-0655

Éditeur

IKER

Édition imprimée

Date de publication : 1 janvier 2016

Pagination : 219-229

ISBN : 978-2-95534-134-6

ISSN : $1273-3830$

Référence électronique

Maia Duguine, «Argumentu isilen tipologia bateratu baten aldeko zenbait argudio», Lapurdum [Linean],

19 | 2016, Sarean emana----an 01 janvier 2021, kontsultatu 03 septembre 2021. URL: http://

journals.openedition.org/lapurdum/3338 ; DOI: https://doi.org/10.4000/lapurdum.3338

Creative Commons - Attribution - Pas d'Utilisation Commerciale - Pas de Modification 4.0 International - CC BY-NC-ND 4.0 


\title{
Argumentu isilen tipologia bateratu baten aldeko zenbait argudio ${ }^{1}$
}

\author{
Maia DUGUINE \\ UPV/EHU
}

1. Argumentu isil aske eta kontrolatuen arteko bereizketa: aitzindariak

Argumentu isilak, perpaus jakin batean fonologikoki gauzatuak ez diren aditzaren argumentuak dira. Horrela, ondoko adibidean joan aditzaren subjektua isila da:

(1) $\varnothing$ mendira joan da.

Jakina da argumentu isilek izaera desberdineko interpretazioak har ditzaketela. Hemen dependentzia harremanen araberako desberdintasunak hartuko ditut aztergai, ondoko bi adibideetan irudikatzen diren kasuetara mugatuz:

(2) Mirenek $_{\mathrm{i}}\left[\varnothing_{\mathrm{i} / \mathrm{j}}\right.$ mendira joan dela $]$ erran du.

(3) Mirenek $_{\mathrm{i}}\left[\emptyset_{\mathrm{i}^{*} / \mathrm{j}}\right.$ mendira joan $]$ nahi du.

Azpindizeek adierazten dutenez, (2)ko perpausean, argumentu isilak perpaus nagusiko Miren subjektuak bezalako erreferentzia ukan dezake, baina ez nahi ala ez: aitzinagoko diskurtsoan erreferente gisa sartu den indibiduo bati ere egin diezaioke erreferentzia. (3)ko perpausean, haatik, argumentu isilaren interpretazioa mugatuagoa da: perpaus nagusiko Miren subjektuak bezalako erreferentzia du halabeharrez, interpretazioa erreferente honekiko dependentea du. Kasu hauetan Miren aitzindariak argumentu isila kontrolatzen duela erraten da; aldagai uztartu baten jokamoldea du. Laburbilduz, adibide hauek argumentu isilek ukan ditzaketen bi interpretazio mota erakusten dituzte: lehen kasuan interpretazioa askea, bigarrenean kontrolatua edo uztartua.

Interpretazioan gauzatzen den desberdintasun horretatik abiaturik, (2)ko argumentu isila eta (3)koa mota desberdineko bi objektu linguistiko direla aintzat hartu izan da aspaldian. Chomskyk (1981) bi kategoria hutsetan bereizten ditu: argumentu askeak pro izendatzen

1. Xarlesi, plazer handiz.

Lan hau ondoko proiektuei esker eraman ahal izan da: IT769-13 (Eusko Jaurlaritza), UFI 11/14 HiTeDI (UPV/EHU), FFI2014-53675-P (Ministerio de Ciencia e Innovación), FFI201451675REDT (Ministerio de Ciencia e Innovación). 
ditu eta dependenteak PRO. Biak kategoria isilak izanik ere, ezaugarri desberdinak dituzte: lehena [-anafora; +izenordain] tasunek definitzen dute eta bigarrena [+anafora; +izenordain] tasunek; bien arteko banaketa Uztardura Teoriak tasun hauen arabera ahalbidetzen duenaren araberakoa da.

Geroztik, Chomskyk (1981) egin kategoria hutsen karakterizazioa baztertu bada ere, pro eta PROren arteko bereizketa mantendu $\mathrm{da}^{2}$. Bereziki, bi kategoria isil hauen sintaxisemantika nasaiki eztabaidatu bada ere (ikus, beste anitzen artean, Hornstein (1999) eta Landau (2000) PRO-ri buruz eta Barbosa (1995), Ordóñez eta Treviño (1999), eta Tomioka (2003) pro-ri buruz), bien arteko banaketa zorrotza mantendu da: objektu desberdinak direlako hipotesia ez da ezbaian ezartzen.

Artikulu labur honen helburua, eztabaida hori irekitzea da, pro eta PRO testuinguru sintaktiko desberdinetan gauzatzen den objektu linguistiko bakar baten emaitzak direlako hipotesia aitzinatuz. Ondoko maneran antolatua da. Bigarren atalak literaturan aintzat hartzen den pro-PRO bereizketaren gibelean den oinarrizko argudiaketa aurkezten du, honen ilunguneak azpimarratuz. Enpirikoki mantentzen ez dela eta bateratzea zentzuduna dela ikusiko dugu. Hirugarren atalak PRO eta proren analisi bateratuak egiten dituen lau aurreikuspen aztertzen ditu. Laugarren atalak erdietsi diren ondorioak laburbiltzen ditu.

\section{Bateratzerantz}

Pro eta PROren arteko diferentzia bistakoena interpretazio desberdina izatera eramaten dituen sintaxi-semantika da: aitzineko atalean ikusi bezala, lehena askea da, eta bigarrenak aldagai uztartu baten ezaugarriak ditu.

Hala ere, bien arteko diferentziak ez dira horretara mugatzen, eta arrunt mota desberdinetako baldintzen mende direla aintzat hartu delako bereizten dira literaturan. Sinpleturik, erran daiteke bakoitzaren banaketa ondoko baldintzen araberakoa dela pentsatzen dela:

- Pro-ren banaketa komunztaduraren ezaugarrien araberakoa da, eta fenomeno honek hizkuntzak bereizten ditu.

Hizkuntza anitzetan beha daitekeen subjektu eta aditzaren arteko komunztaduraren 'aberastasuna' eta pro motako subjektu isilak posible izatearen arteko erlazioaren ondorioz (Taraldsen 1981), analisi anitzek pro-ren baimentzea komunztaduraren edo flexioaren ezaugarrien bitartez egiten dela proposatu dute (Barbosa (1995), Alexiadou \& Anagnostopoulou (1998), Ordóñez eta Treviño (1999)). Komunztaduraren ezaugarri horiek hizkuntzaz hizkuntza aldatzen direnez, hizkuntza batzuetan subjektu isilak baimenduak izanen dira eta besteetan ez.

- PRO-ren banaketa 'jokatugabetasuna'-ren araberakoa da, eta fenomeno honek perpaus motak bereizten ditu.

PROren banaketa anitzetan gauzatutako subjektuen banaketarekiko kontrajarria da:

2. Eztabaida segitzeko errazagoa egiteko, eta tradizioari jarraiki, argumentu isil askeak pro izendatuko ditut eta dependenteak PRO. Izendapen hori deskriptiboa da, ez du analisi berezirik ekartzen berekin; hain justu, biek izaera ber-bera dutela proposatuko dut. 
gauzatutako subjektuek kasua jaso behar dute eta PROk ezin du, edo gauzatutako subjektuak gobernatuak izan behar dira eta PROk ezin du, edo gauzatutako subjektuek denbora eta komunztadura tasunak dituen Infl buru bat behar du eta PROk ez, etab. (ikus besteren artean Chomsky (1981), Hornstein (1999), Landau (2004). Oro har, perpaus jokatuetako ezaugarri batek ditu subjektu gauzatuak posible egiten eta PRO ezinezko ${ }^{3}$.Hortaz, PRO eta gauzatutako subjektuak banaketa osagarrian dira, eta honek bat egiten du perpaus jokatu eta jokatugabeen arteko banaketarekin.

Badira haatik bai pro-ren eta bai PRO-ren fenomenoen definitzeko bide hauek hein handi batean bide makurretik doazela pentsatzeko arrazoiak.

Aitzineko zenbait lanetan, argudiatu dut pro-ren banaketa ez dela -zuzenean bederenkomunztaduraren ezaugarrien ondorioa (Duguine 2013). Euskarak argi erakusten du hori: perpaus jokatuetan komunztadura aberatsarekin bat egiten badu ere (ikus (4)), subjektu isilen fenomenoa komunztadurarik gabeko perpausetara ere hedatzen da (ikus ere Ortiz de Urbina (1989), Elordieta (2001)). (5)eko mendeko perpaus jokatugabeko subjektuak edozein diskurtso aitzindariri egin diezaioke erreferentzia. Hots, pro motakoa da.

pro sobera mintzatzen da.

(5) Testuingurua: kalakaria den lagun batekin iragan dut eguna. [pro ${ }_{i}$ hainbeste mintzatzeak] ni ${ }_{j}$ akitzen nau.

Paraleloan, Duguine (2013) lanaren emaitzetako baten arabera, pro-drop fenomenoan behatzen den hizkuntzaz hizkuntzako aldakortasuna (hizkuntza batzuk pro subjektuak ez baimentzea, eta baimentzen dituztenen artean pro-ren banaketa modelo arrunt desberdinak izatea) gramatikaren ezaugarri independenteen ondorioa da. Gainera, hizkuntza guztiek berez argumentuak isiltzeko aukera dutela iduri luke. Horrenbestez, pro-dropen sintaxiaren inguruko eztabaidaren funtsa ez da hizkuntza aldakortasunean oinarritu behar (hots, ez da Pro-drop Parametrorik). Laburbilduz: hipotesi estandarrak dionaren kontra, ez dirudi pro-drop fenomenoa komunztaduraren ezaugarrien araberakoa denik, eta ez ditu hizkuntzak bereizten.

Bere aldetik, PROren analisi estandarrak ere arazoak ditu. Horrela, hainbat hizkuntzetan, arrunt jokatugabeak ez diren perpausetan ere baimenduak dira PRO motako subjektu isil dependenteak (Landau 2004). (6)k grezierazko subjuntiboko perpaus baten adibidea ematen du ('kontrol finituari' buruz, eta fenomeno hau ikustera ematen duten hizkuntzen zerrenda luzeago baterako, ikus Landau 2013: 88):

(6)

$\begin{array}{llllll}\text { O } & \text { Yanis } & \text { kseri } & \text { na } & \text { kolimbai } & \text { Greziera } \\ \text { DET } & \text { Yanis.NOM } & \text { daki } & \text { PRT } & \text { igeri.egin.3sg } & \text { (Varlokosta 1993) } \\ \text { 'Yanisek badaki nola igeri egin.' } & & \end{array}$

3. Jokatutasuna eta jokatugabetasunaren karakterizazio intuitibo bat segituko dut hemen. Xehetasun gehiagorako, ikus adibidez Landau $(2000,2004)$. 
Laburbilduz, ez da argi proren banaketak komunztaduraren banaketarekin bat egiten duenik, eta PROren banaketak jokatugabetasunarekin bat egiten duenik.

Haatik, bi kategoria isil hauek bata bestearekin banaketa osagarrian direla argudiatu liteke. (2)-(3)ko pareak hala iradokitzen du: zenbait testuinguru sintaktikotan subjektu gunean pro egon daiteke, besteetan PRO besterik ez.

Literaturan derrigorrezko kontrol egiturak (obligatory control, OC) eta kontrolik gabeko egiturak bereizten dira (non-control, NC). OC egituretako subjektu isila PRO motakoa da. Honen ezaugarriak zehazki definituak izan dira (ikus adibidez Landauren (2013: 74) 'OC-ren sinadura'), eta identifikatzeko diagnosi multzo bat erabiltzen da (besteren artean: kontrolatzailea o-komando harremanean eta lokala izateko beharra, elipsi pean irakurketa zurruna ukaiteko ezintasuna, galdegai-partikula batekin lotua den kontrolatzailearekin erreferentziakide izateko ezintasuna; ikus Hornstein 1999, Landau 2000, 2013). Diagnosi guzti hauetan, proren emaitzak PROren emaitzen kontrakoak dira (ikus Duguine 2013: 3. kapitulua). Hortaz, OC egituretako PRO ez den subjektu isil oro pro dela erran genezake. Hau da preseski Hornsteinek (1999) egiten duen analisia (ikus ere Boeckx, Hornstein \& Nunes 2010). Emaitza hori ontzat hartzen baldin badugu, gorago aipatu orokorpena indartzen dugu: PRO eta pro banaketa osagarrian dira, bata ez dugunean bestea dugu4.

Banaketa osagarria, badakigu, azalean bi objektu direnak sakonean bakarra direlako seinale da. Honenbestez, argudiaketak ondoko emaitzara eramaten gaitu modu naturalean: pro eta PRO espresio isil bakarraren bi gauzatze dira. Honenbestez, ezaugarri sintaktiko eta semantiko desberdinak baldin badituzte, beren izaeraz kanpoko arrazoiengatik izanen da. Ondorio honek arrunt berria ez den ideia batera eramaten gaituela aitortu behar da, Borer-ek (1989) eta Huang-ek (1989) jadanik modu independentean pro eta PROren analisi bateratuak proposatu baitzituzten Gobernu eta Uztarduraren modeloaren baitan. Sekula nagusitu ez zen hipotesi hori, beraz, indar berri batekin berpizten zaigu hemen.

Hemen egina laburbildu dezagun. Subjektu isil askeak eta kontrolatuak bereizi ohi direla ikusi dugu. Hala ere, bakoitza fenomeno independente gisa karakterizatzen duten analisiak dudagarriak dira, eta derrigorrezko kontrolaren ezaugarriak kontutan hartzen baldin baditugu, fenomeno bakarraren bi aurpegi besterik ez direla ondorioztatu dezakegu.

Ondoko atalean, atal honetan lortu dugun emaitza indartzeko xedearekin, pro eta PROren bateratzearen hipotesiak gauzatutako DSen jokamoldearekiko egiten dituen zenbait aurreikuspen aztertzen ditut.

\section{Hipotesiaren aurreikuspenak: pro, PRO eta gauzatutako DSak}

Pro eta PRO kategoria bakar batean bildu nahi izanik, argitu beharreko lehen galdera begi-bistakoa egiten da: zer da kategoria hori? Hau da: nolako izaera sintaktiko, semantiko eta fonologikoa du argumentu aske eta dependenteak ahalbidetzen dituen fenomenoak?

Ez naiz eztabaida horretan sartuko artikulu labur honetan, helburuak bestelakoak (eta umilagoak) direlako hemen. Aitzinetik egin lanean oinarriturik, pro motako argumentu isilak

4. Baina ikus Landau (2013) bestelako ikuspegi baterako. 
fonologikoki isilduak edo ezabatuak diren DSak direla aintzat hartuko dut (Duguine (2013, 2014); ikus ere besteren artean Kim (1999), Tomioka (2003), Saito (2007) eta Takahashi (2008) japoniera eta koreerazko argumentu isilez). Hipotesi honen arabera, pro-drop hizkuntzetan, DSek zenbait baldintza (sintaktiko, semantiko eta morfo-fonologiko) betetzen badituzte, fonologikoki isilduak izan daitezke.

Azterbide honen ondorio teoriko inportanteetako bat ondokoa da: maila sintaktiko eta semantikoan ez da pro eta DSen arteko diferentziarik. Itzul gaitezen orain aitzineko atalean proposatu hipotesira, erran nahi baita pro eta PRO motako argumentu isilak sail berekoak direlako hipotesira. Zuzena baldin bada, orduan PRO ere isildu edo ezabatutako DS bat da, eta honenbestez, prorekin gertatzen den bezala, ez litzateke PRO eta gauzatutako subjektuen arteko alde sintaktiko eta semantikorik izan beharko.

Atal honetan aurreikuspen honen lau alderdi aztertuko ditugu, pro eta PRO funtsean fenomeno bakarraren bi alderdi direlako hipotesiak oinarri enpirikoa duela erakutsiz.

\subsection{PRO eta subjektu gauzatuak}

Pro motako argumentu isilak gauzatutako subjektuekin aldizkatzen dira (euskaraz zein beste pro-drop hizkuntzetan), eta iduri luke gaitasun hori orokorra dela5:

$$
\text { pro/hura/Miren mendira joan da. }
$$

Aldizkatze hori, pro gauzatutako argumentuen baliokide isila delako seinaletzat hartua izan da anitzetan. Horrela, pro tasun fonologikorik gabeko izenordaina dela proposatua izan da (ikus Chomsky 1981, Neeleman \& Szendröi 2007, Holmberg 2010), edo ezabatutako izen/ determinatzaile sintagma (DS) (Kim 1999, Tomioka 2003, Saito 2007).

Pro halakoa izanik, PRO eta pro funtsean objektu bera direlako hipotesiak PRO ere izenordain edo izen sintagma isila dela iradokitzen du. Ondorio honek aurreikuspen argia egiten du, atalaren sarreran azpimarratutakoaren bidetik: pro bezala, PRO ere gauzatutako subjektuekin alternantzian gertatzen dela behatu beharko genuke.

Baina literaturan nagusi den orokorpena oinarritzat hartuz gero, aurreikuspena betetzen ez dela ondorioztatuko genuke. Izan ere, PRO eta DSak banaketa osagarrian direla aintzat hartzen da tradizionalki (Chomsky 1981).

Azken urte hauetan, haatik, baieztapen hori dudan jarri da. Horrela, hizkuntza anitzetan PRO gauzatutako subjektuekin aldizkatu daitekeela erakutsi da. Ondoko ingelesezko gerundioan beha daiteke aldizkatze hau (ikus Pires 2007):

$$
\text { John favored }\left[\mathrm{PRO}_{\mathrm{i}} /\right. \text { Anna moving to Italy]. }
$$

5. Aldagai uztartua den kasu batzuetan pro besterik ez dela posible argudiatu izan da (ikus bereziki Montalbetti 1984). Hala ere, hau ez da hizkuntza guztietan behatzen, eta horrek arrazoi independenteek eragiten duten efektua dela iradokitzen du. 
Gisa berean, Sundaresan eta McFaddenek (2009) tamilera hizkuntza dravidarreko (9) ko adibidea ematen dute, eta haiekin batera azpimarratu genezake gisa bereko aldizkatzeak gertatzen direla beste hainbat hizkuntzatan, hala nola malabareraz (beste hizkuntza dravidarra; Sundaresan \& McFadden 2009), sinhalaz (indoariarra; Sundaresan \& McFadden 2009), greko zaharrean (Andrews 1971), latinez (Rouveret \& Vergnaud 1980), irlanderaz (McCloskey 1985), mendebaldeko flandrieraz (Haegeman 1985) eta hainbat hizkuntza erromantzetan (ikus adibidez Mensching 2000) .
a. $\operatorname{Raman}_{\mathrm{i}} \quad\left[\mathrm{PRO}_{\mathrm{i}}\right.$ puuri porikk-a] maavu vaangi-n-aan. Raman.NOM puuri.AKUS frijitu-INF irin.AKUS eros-IRAG-m.3sg 'Ramanek irina erosi zuen puuriak frijitzeko/frijitzerakoan.'
b. Raman [Vasu puuri porikk-a] maavu vaangi-n-aan. Raman.NOM Vasu.NOM puuri.AKUS frijitu-INF irin.AKUS eros-IRAG-m.3sg 'Ramanek irina erosi zuen Vasuk puuriak frijitzeko/frijitzerakoan.'

Tamilera (Sundaresan \& McFadden 2009)

Pro bezala, beraz, PRO gauzatutako DSekin aldizkatze askean ikus daiteke hainbat hizkuntza edo testuinguru sintaktikotan.

Euskarak ere aldizkatze horren zenbait adibide eskaintzen ditu. Hona hemen Artiagoitiak (2003) biltzen duen pare bat (ikus ere Duguine 2013):

(10) a. Gurasoek $\left[\mathrm{PRO}_{\mathrm{i}}\right.$ film hori ikustea] galarazi diote Amaiari.

b. Joni eta Mireni debekatu diet [semeek elkar ikustea].

[Artiagoitia (2003: 711), (10b) Salaburu (1986: 399)-tik egokitua]

Laburbilduz, PRO eta pro bateratzen dituen hipotesiaren ikuspegitik, eta biak isildu edo ezabatutako DSak direla aintzat harturik, PRO gauzatutako DSekin aldizkatzea espero daiteke. Hemen aipatu datuek erakusten dutenez, preseski, PRO/DS aldizkatzeak ez dira batere marjinalak hizkuntzetan zehar.

\subsection{PROren gauzatutako baliokidea}

Lantxo honetan aztertzen dugun hipotesiaren arabera, pro eta PRO funtsean kategoria isil bakarraren bi aurpegi dira. Horrek erran nahi du bataren irakurketa askea eta bestearen irakurketa dependentea ez direla berezkoak, baizik eta perpausaren bestelako ezaugarrien emaitzak. Bestalde, gorago aintzat hartu hipotesiaren arabera, espresio isil hau isiltze edo ezabaketa fonologiko baten emaitza litzateke. Bi ideia hauek biltzeak harago eramaten gaitu beraz: isiltzeak ez duenez neholako eraginik interpretazioan, orduan posizio jakin batean den subjektuak ezaugarri sintaktiko eta

6. San Martinek (2004: 139) lehenago ere azpimarratu zuen gaztelaniaz, portugesez, euskaraz, sardinieraz, flandrieraz eta malabareraz perpaus jokatugabeetan DSak baimentzen direla subjektu gunean. 
semantiko jakin batzuk izanen ditu, zan dadin fonologikoki gauzatua ala isila.

Partikularki, espero izatekoa litzateke PRO bezala nahi ala ez kontrolatuak diren gauzatutako DSak izatea gramatikan, eta hauek PROren kokagune beretan agertzea. Izan ere, gure hipotesiaren arabera PRO ezabatutako subjektu bat izanik, bere aldagai uztartu izaera ez da izanen isila izatearen ondorioa, baizik eta DSak berak duen ezaugarri bat.

Euskaraz aurreikuspena betetzen da. Tipikoki PROrenak diren subjektu posizioetan, perpaus jokatugabe multzo handi batean, gauzatutako subjektu bat egon daiteke. DS hori, haatik, ez da aitzineko azpiatalean deskribatu bezalakoa: kasu honetan, ez du erreferentzia askea, eta PRO bezala, kontrolatua da (ikus Artiagoitia 2003, Duguine 2013, Rezac-eta 2014). Beha (11):

(11) Jon $\mathrm{i}_{\mathrm{i}}$ domina $\left[\mathrm{PRO}_{\mathrm{i} /{ }^{*} \mathrm{j}}\right.$ /berak $_{\mathrm{i} /{ }^{*} \mathrm{j}}$ irabaztera] etorri da.

Adibide honetan, mendeko perpauseko subjektua PRO izan dadin ala berak erakusle ergatiboa, irakurketa kontrolatua besterik ez du baimentzen ${ }^{7}$. Gisa bereko aldizkatzeak behatuak izan dira beste hainbat hizkuntzatan, hala nola hungarieraz, errumanieraz, gaztelaniaz, italieraz, portugesez, koreeraz (ikus Borer 1989, Szabolcsi 2009, Barbosa 2009, Livitz 2014). Hona italierazko adibide bat:

(12) Ogni ragazzo / Gianni odierebbe [andare solo/anche lui a Milano]. guzti mutil Gianni gorroto.luke joan.INF bakarrik/ere bera Milanora 'Mutil orok/Giannik gorroto luke [bera bakarrik/ere Milanora joatea].

(Szabolcsi 2009)

Honenbestez, pro eta PROren analisi bateratuak aurreikusten duen moduan, PROk badu fonologikoki gauzatzen den baliokide bat hainbat hizkuntzatan: kontrolatua den izenordaina edo erakuslea.

\subsection{Aldizkatzeen patroi orokorra}

PROrekin aldizkatzen diren subjektuek honek bezalako ezaugarri sintaktiko eta semantikoak dituzten bezala, prorekin aldizkatzen direnek bigarren honek bezalakoak ukaitea esperoko genuke. Pro erreferentzia askekoa dela ikusi dugu eta, jakina denez, hala dira ere harekin aldizkatzen diren gauzatutako subjektuak: berezko erreferentziarako gaitasuna dute:

$$
\text { pro/hura/Miren/ene anaia mendira joan da. }
$$

Honekin bat egiten du literaturan oraino aintzat hartzen den proren karakterizazioak, hala nola izenordainen ezaugarriak dituela (ikus besteren artean Chomsky 1981, Neeleman

7. Duguinek (2013: 3. kapitulua) erakusten du egitura hauetan PRO eta gauzatutako subjektuaren baliokidetza semantikoa orokorra dela, eta biek derrigorrezko kontrol egituretako subjektuen ezaugarriak dituztela. 
\& Szendröi 2007, Holmberg 2010). Izenordainen deskribapen estandarraren arabera, ezin dira eremu lokalean uztartuak izan (ikus adibidez Chomsky 1981). Hortaz, analisi klasikoaren ikuspegitik ere gure aurreikuspena betetzen dela erran daiteke ${ }^{8}$.

Hemen agertzen den patroi orokorrak, beraz, gure hipotesiek egin aurreikuspenak baieztatzen ditu: alde batetik, PRO eta DS kontrolatuen arteko aldizkatzea dugu, eta bestetik pro eta DS askeen artekoa.

Euskaraz, pro baimendua den testuinguru sintaktiko guztietan DS askeak baimenduak dira. (11) adibideko izenordain kontrolatuen gisakoak beti PROrekin aldizkatzen dira (Artiagoitia (2003), Euskaltzaindia (2011) eta Duguine (2013) lanetatik atera daitekeen orokorpena).

Kontradibide bat dugula iduri luke, haatik, kontrako konfigurazioan: 3.1 atalean ikusitakoaren arabera, PRO baimendua den testuinguru sintaktikoetan gauzatzen diren subjektuak ez dira beti kontrolatuak; hauek askeak izan daitezke. Bestela erranik, PRO bai DS kontrolatuekin (ikus (11)) bai DS askeekin aldizkatzen da (ikus (8)-(10)).

Baina salbuespen hauek badute azalpen bat. Alde batetik, ohar gaitezen egitura hauek kontrolatutako subjektua onartzen dutela:

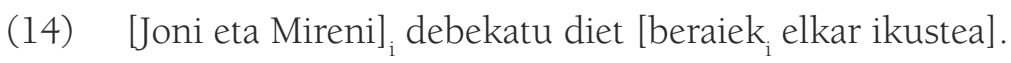

Hau da, egitura hauetan gauzatutako subjektuak bi motakoak izan daitezke: kontrolatuak edo askeak. Subjektu isila halabeharrez kontrolatua izateak, haatik, isiltzea bera subjektu kontrolatuei bakarrik aplikatu dakiekeela iradokitzen du. Ideia honi jarraiki, proposatu nahi nuke PRO/ DS aske aldizkatzea isiltze operazioa erregulatzen duten murriztapenen bitartez esplikatu behar dela.

Onartua da perpaus bateko osagaiak isiltzea baldintzatua dela, horretarako baldintza batzuk bete behar direla (ikus adibidez Johnson 2001). Pro motako subjektu isilak baimentze sintaktiko baten mende direla erran ohi da. Lan klasikoetan (Rizzi 1986, Jaeggli \& Safir 1989, Oyharçabal 1991), baldintzetako bat Kasu posizioan izatea da. Independenteki, Duguinek (2013) egiturazko Kasua argumentu isil askeen baimentzerako ezinbestekoa dela argudiatzen du, (11) bezalako kasuetan subjektuari egiturazko Kasurik esleitzen ez zaiola erakutsiz. Azterbide hau zuzena izanik, PRO/DS aske aldizkatzeak azaltzeko modu bat genuke: ez zaienez kasurik ezartzen, DS askeak ezin dira isildu (ez da beraz pro motako subjektu isilik gauzatuko), baina DS kontrolatuak isil daitezke, eta hortaz aldizkatzea PRO motako subjektu isilekin eginen da bakarrik.

\subsection{Aldakortasuna}

Hemen proposatu sistemak hizkuntza aldakortasunari begira ere aurreikuspenak egiten ditu. Oro har, espero dugu bi hizkuntzak edo bi aldaerak egitura batean jokamolde desberdina erakusten badute, batak DS askeak baimenduz eta besteak DS kontrolatuak

8. Ohar hala ere argudio hau ikuspegi klasikoan oinarritzen den idealizazioa dela eta gauzak ez direla hain sinpleak, 3.2 atalean ikusi bezala, erreferentzia kontrolatua duten gauzatutako subjektuak ere izenordainak izan baitaitezke. 
besterik ez, jokamolde desberdintasuna subjektuen ezaugarrietan ere ikusi ahal izanen dela, lehen kasuan aldizkatzea prorekin izanez eta bigarren kasuan PROrekin.

Jakina da perpaus jokatugabeetako subjektuen jokamoldea ez dela bera euskararen aldaera guztietan, eta kasu batzuetan desberdintasunak idiolekto mailan ere beha daitezkeela (ikus Artiagoitia 2003, Euskaltzaindia 2011). Agindu aditzen osagarri 'nominalizatuak' har ditzagun. Hauek, agindu, erregutu, esan/erran, eskatu, eta iradoki aditzen gisakoek hautatuak dira eta -tzeko atzizkia buru duten perpausak dira.

Helburu xumea finkatuz, esan aditzaren kasura mugatuko naiz hemen, datuak arrunt argiak baitira eta gure lanerako interesgarriak. Artiagoitiak (2003: 704), aditz honekin subjektua gauzatua izan daitekeela dio (beste aditz batzuekin ere adibideak aurki daitezkeela dio, baina hain argiak ez direla azpimarratuz):

Mendeko perpauseko subjektua DS askea izanik, ezabaketaren hipotesiak ondoko aurreikuspena egiten du: isildutakoan, irakurketa askea mantenduko du. Ondoko adibideak erakusten duenez, Artiagoitiak (2003: 704) deskribatzen dituen datuetan hala da:

(16) Aitak Amaiari $\left[\right.$ pro $_{\mathrm{i}, \mathrm{j}}$ hona etortzeko] esan dio.

(Artiagoitia 2003: 704)

Artiagoitiaren deskribapenetik kanpo gelditzen den datu bat hau da: (15) ez da euskal hiztun guztientzat gramatikala. Zehazkiago, nafar-lapurteraren hiztun anitzentzat esan/ erran aditzak hautatu -tzeko perpausetan ezin da subjektu askerik egon (maila honetan patroi hau duten hiztunen multzoa zehazkiago definitu ezinean, B aldaera deituko dut). Haatik, izenordain kontrolatuak baimenduak dira:

\section{(17) Aitak Amaiari ${ }_{1}\left[{ }^{*}\right.$ gu/bera ${ }_{i}$ hona etortzeko] esan dio.}

[B aldaera]

Gauzak horrela, aldaera honen kasuan gure sistemak egiten duen aurreikuspena, posizio honetako subjektua ere nahi ala ez kontrolatua izanen dela da, eta hortaz, (16) ez dela gramatikala izanen. Berriz ere, datuek aurreikuspena egiaztatzen dute:

\section{(18) Aitak Amaiari ${ }_{1}\left[{ }^{*}\right.$ pro/PRO ${ }_{i}$ hona etortzeko] esan dio.}

[B aldaera]

Hizkuntza aldakortasuneko datu hauek, honenbestez, gure hipotesia baieztatzen dute, DS askeak subjektu isil askeekin aldizkatzen baitira eta DS kontrolatuak subjektu isil kontrolatuekin ${ }^{9}$.

9. Hala ere, hemen iradokitzen dena baino konplexutasun maila handiagoa bada euskararen aldaera guztiak kontuan hartzen baditugu, hiztun batzuk 3.1 atalean deskribatutako PRO/DS aske aldizkatzea baimentzen baitute egitura hauetan (ikus Duguine 2013: 3. kapitulua). Kasu hauen azalpena 3.3 atalean iradoki dudanaren bidetik joanen litzateke. 


\section{Ondorioak}

Artikulu labur honetan, pro eta PRO testuinguru sintaktiko desberdinetan gauzatzen den objektu linguistiko bakar baten emaitzak direlako hipotesia aitzinatu dut. Literaturan aintzat hartzen den pro-PRO bereizketaren gibelean den oinarrizko argudiaketaren akatsetan oinarriturik, batzea zentzuduna litzatekeela erakutsi dut, eta hipotesiak gauzatutako DSen jokamolde eta ezaugarriekiko egiten dituen zenbait aurreikuspen aztertu ditut.

\section{Erreferentziak}

Alexiadou, Anastasia \& Elena Anagnostopoulou. 1998. Parametrizing AGR: Word Order, Verbmovement and EPP checking. Natural Language and Linguistic Theory 16: 491-539.

Andrews, Avery D. 1971. Case agreement of predicate modifiers in Ancient Greek. Linguistic Inquiry 2: 127-151.

Artiagoitia, Xabier. 2003. Complementation. In José Ignacio Hualde \& Jon Ortiz de Urbina (arg), A Grammar of Basque, 640-718 Berlin: Mouton de Gruyter.

Barbosa, Pilar. 2009. A case for an Agree-based theory of control. Ms., Universidade do Minho. Barbosa, Pilar. 1995, Null subjects, Doktorego tesia, MIT.

Boeckx, Cedric, Norbert Hornstein \& Jairo Nunes. 2010. Control as movement. Cambridge: Cambridge University Press.

Borer, Hagit. 1989. Anaphoric Agr. In Osvaldo Jaeggli \& Kenneth Safir (arg), The Null Subject Parameter, 69-109. Dordrecht: Kluwer Academic Publishers.

Chomsky, Noam. 1981. Lectures on Government and Binding. Cambridge: Mouton de Gruyter.

Duguine, Maia. 2013. Null arguments and linguistic variation: a minimalist analysis of pro-drop. Doktorego tesia, Université de Nantes \& UPV/EHU.

Euskaltzaindia. 2011. Euskal Gramatika: lehen urratsak VII (Perpaus jokatugabeak), Bilbao: Euskaltzaindia.

Haegeman, Liliane. 1985. INFL, COMP and nominative case assignment in Flemish infinitivals. In Pieter Muysken \& Henk van Riemsdijk (arg.), Features and Projections, 123-137. Dordrecht: Kluwer.

Holmberg, Anders. 2010. Null subject parameters. In Theresa Biberauer, Anders Holmberg, Ian Roberts \& Michelle Sheehan (arg), Parametric variation, 88-124. Cambridge: Cambridge University Press.

Hornstein, Norbert. 1999. Movement and control. Linguistic Inquiry 30: 69-96.

Huang, C. T. James. 1989. Pro-drop in Chinese: a generalized control theory. In Osvaldo Jaeggli \& Kenneth Safir (arg), The Null Subject Parameter, 185-214. Dordrecht: Kluwer Academic Publishers.

Jaeggli, Osvaldo \& Kenneth Safir 1989. The null subject parameter and parametric theory. In Osvaldo Jaeggli \& Kenneth Safir (arg.), The null subject parameter, 185-214. Dordrecht: Kluwer Academic Publishers.

Johnson, Kyle. 2001. What VP ellipsis can do, and what it can't, but not why. In Mark Baltin \& Chris Collins (arg.), The handbook of contemporary syntactic theory, 439-479. Oxford: Blackwell. 
Kim, Soowon. 1999. Sloppy/strict identity, empty objects, and NP ellipsis. Journal of East Asian Linguistics 8: 255-284.

Landau, Idan. 2000. Elements of control: Structure and meaning in infinitival constructions. Dordrecht: Kluwer Academic Publishers.

Landau, Idan. 2004. The scale of finiteness and the calculus of control. Natural Language $\&$ Linguistic Theory 22: 811-877.

Livitz, Inna. 2014. Deriving silence through dependent reference: Focus on pronouns. Doktorego tesia, New York University, New York.

McCloskey, James. 1985. Case, movement and raising in Modern English. In Proceedings of WCCFL 4, 190-205.

Mensching, Guido. 2000. Infinitive constructions with specified subjects. Oxford: Oxford University Press.

Montalbetti, Mario. 1984. After binding: On the interpretation of pronouns. Doktorego tesia, MIT.

Neeleman, Ad \& Krizsta Szendröi. 2007. Radical pro-drop and the morphology of pronouns. Linguistic Inquiry 38: 671-714.

Ordóñez, Francisco \& Esthela Treviño. 1999. Left-dislocated subjects and the pro-drop parameter, Lingua 107: 39-68.

Oyharçabal, Beñat. 1991. Théorie des pronoms nuls et diversité linguistique: Bilan. In Joseba A. Lakarra (arg.), Memoriae Mitxelena Magistri Sacrum, Supplements to ASJU, 867-898. Donostia: UPV/EHU.

Rezac, Milan, Pablo Albizu \& Ricardo Etxepare. 2014. The structural ergative of Basque and the theory of case. Natural Language and Linguistic Theory 32: 1273-1330.

Rizzi, Luigi 1986. Null objects in Italian and the theory of pro. Linguistic Inquiry 17: 501-557.

Rouveret, Alain \& Jean-Roger Vergnaud. 1980. Specifying reference to the subject. Linguistic Inquiry 11: 97-202.

Saito, Mamoru. 2007. Notes on East Asian argument ellipsis. Language research 43: 203-227.

San Martin, Itziar. 2004. On subordination and the distribution of PRO. Ph.D. Dissertation, University of Maryland.

Sundaresan, Sandhya \& Thomas McFadden. 2009. DP distribution and finiteness in Tamil and other languages: Selection vs. Case. Journal of South Asian Linguistics 2: 5-34.

Sundaresan, Sandhya. 2014. Making sense of silence: finiteness and the (OC) PRO vs. pro distinction. Natural Language and Linguistic Theory 32: 59-85.

Szabolcsi, Anna. 2009. Overt nominative subjects in infinitival complements crosslinguistically: Data, diagnostics, and preliminary analyses. NYU Working Papers in Linguistics 2.

Takahashi, Daiko. 2008. Noun phrase ellipsis. In Shigeru Miyagawa \& Mamoru Saito (arg), The Oxford Handbook of Japanese linguistics, 394-422. Oxford: Oxford University Press.

Taraldsen, Tarald. 1980. On the Nominative Island Condition, vacuous application and the That-Trace Filter. Bloomington: Indiana University Linguistics Club.

Tomioka, Satoshi. 2003. The semantics of Japanese null pronouns and its cross-linguistic implications. In Kerstin Schwabe \& Susan Winkler (arg.), The interfaces: deriving and interpreting omitted structures, 321-339. Amsterdam: J. Benjamins. 